\title{
Internacionalização, humanismo e ética ${ }^{1}$
}

Antenor Ferreira Corrêa ${ }^{2}$ Universidade de Brasilia (UnB) antenorferreira@yahoo.com.br 


\section{Resumo}

Este artigo traz apontamentos a respeito do processo de internacionalização nas universidades públicas do Brasil, com foco na internacionalização dos programas de pós-graduação, além de serem discutidos os objetivos intencionados com a realização de cooperações internacionais. A seguir, tendo como base a experiência adquirida em projetos de colaboração internacional, proponho repensar o processo de internacionalização à luz de uma perspectiva humanista, na qual as relações interpessoais são redimensionadas e arroladas como resultados objetivados nas cooperações interinstituicionais. $O$ resultado esperado com a adoção desse aporte humanista é a transformação ética dos envolvidos em experiências de mobilidade acadêmica.

Palavras-chave: internacionalização, humanismo, expectativa de honestidade, ética.

\section{Abstract}

I offer some considerations regarding the internationalization process in Brazilian public universities. The focus of this discussion is the internalization of graduate programs. The ordinary expected outcomes from an international cooperation are inquired. Following, I purpose a rethinking of internationalization process in the light of a humanistic perspective. This proposition is based on my experience as a coordinator of projects of international collaboration. In a humanistic point of view, interpersonal relationships are enhanced and also intended as outcomes from inter-institutional cooperation. The expected result with the adoption of this humanist approach is the ethical transformation of the participants in experiences of academic mobility.

Keywords: internationalization, humanism, honesty expectation, ethics.

\footnotetext{
1 O presente trabalho foi realizado com apoio da Coordenação de Aperfeiçoamento de Pessoal de Nível Superior - Brasil (CAPES) - Código de Financiamento 001.

2 Pós-Doutorado pela Universidad de Granada, 2019 (bolsa Fundación Carolina y Grupo Tordesillas). Pós-Doutorado pela University of California, Riverside, 2015 (bolsa Capes). Doutorado em Música pela ECA-USP, 2009 (bolsa Capes). Mestrado em música pela Unesp (Universidade Estadual Paulista Júlio de Mesquita Filho, 2004) e Bacharelado em Música, habilitação em Composição e Regência, pela Unesp (Universidade Estadual Paulista Júlio de Mesquita Filho, 2001). Professor associado I da UnB (Universidade de Brasília). Professor permanente do Programa de Pós-Graduação em Artes Visuais da UnB, linha de pesquisa Arte e Tecnologia. Coordenou programa de intercâmbio com a Universidade de Örebro, Suécia (2012-2017), convênio patrocinado pelo Linnaeus-Palme Programme.
} 


\section{Introdução}

Inicio este artigo relatando dois episódios que, além de explicitarem a motivação para a escrita deste texto, também deixam claro os dois aspectos centrais sobre os quais discorrerei, a saber: ética e humanismo. Esses dois tópicos, por sua vez, serão, adiante, definidos e contextualizados no âmbito das discussões e dos planejamentos sobre a internacionalização nas instituições de ensino superior do Brasil.

Quando lecionei na Universidade de Örebro (Suécia), participando de um programa de intercâmbio ao nível da graduação, programa este integralmente subvencionado pela fundação Linnaeus-Palme (Internationella Programkontoret), havia levado do Brasil alguns instrumentos de percussão. Em uma das minhas aulas sobre gêneros musicais brasileiros, notei que o professor de percussão daquela universidade olhava com interesse para a zabumba que eu tocava. Ao final da aula, ele veio até mim e perguntou se eu achava importante que a universidade também possuísse uma zabumba. Eu disse que sim, pois sabia que eles estavam interessados em expandir o curso de percussão latina, de modo a abarcar gêneros musicais de outros países, tais como o Brasil. Desse modo, se houvesse um instrumento à disposição, os alunos poderiam estudá-lo. Até me ofereci para indicar algumas lojas de instrumentos musicais nas quais aquele instrumento poderia ser comprado. Ele então perguntou se eu não estaria interessado em vender o meu próprio instrumento. Eu disse que sim. Após uma breve conversa, acertamos o preço. Ele pediu, então, que eu aguardasse, porque consultaria o diretor do Departamento de Artes. Após 10 minutos ele voltou com um cheque emitido pela secretaria do departamento. Como estou acostumado com a burocracia brasileira, obviamente fiquei pasmado e curioso. Perguntei se não haveria a necessidade de emissão de qualquer tipo de nota fiscal ou recibo. Ele disse que não, pois o instrumento lá estando era a comprovação da compra e, quando eu depositasse o cheque, ficaria, consequentemente, atestado o valor pago. Uma compra dessa mesma natureza no Brasil tardaria, pelo menos, seis meses e acumularia uma quantidade insana de documentos. A pergunta que ficou em minha mente após essa venda foi: por que as coisas são tão burocratizadas no Brasil? A resposta será oferecida na terceira parte deste artigo, cujo subtítulo é aquilo que nos falta neste país: expectativa de honestidade.

Quando realizava meu pós-doutorado na Universidade de Granada (Espanha), fui conversar com o diretor da Escuela Internacional de PosGrado para saber dos procedimentos para a implementação de orientações em regime de cotutela. Ele me informou que "acordos de cotutela são bem simples": o professor do programa de pós-graduação da Universidade de Granada que aceitasse o aluno brasileiro em regime de cotutela deveria enviar um e-mail à Escola Internacional de Pós-Graduação confirmando esse aceite. A partir daí, esse próprio escritório contataria o aluno pedindo que enviasse cópia do passaporte e comprovante de matrícula em um programa de pós-graduação no Brasil. Ao receber e conferir essa documentação, o escritório emitiria o documento para que o estudante brasileiro pudesse solicitar o visto. Obtendo seu visto, o aluno viria quando fosse acordado entre os professores responsáveis. Voltando ao Brasil, informei 
à coordenação do PPG que gostaria de estabelecer uma orientação em cotutela e que já havia entrado em acordo com a professora e com o escritório responsável da universidade espanhola. Fui orientando a procurar a assessoria de assuntos internacionais da UnB, onde me informaram da necessidade de abrir um processo oficial para essa finalidade. Resumidamente, somente para início dos trâmites desse processo, se fazia necessária a inserção de mais de 20 documentos, dentre estes, cópias de documentos pessoais de aluno e dos professores, além de atas e pareceres emitidos por pelo menos três departamentos (e/ou decanatos) da UnB. A comparação entre essas duas situações me faz pensar no tipo de tratamento oferecido aos discentes e docentes nas IES brasileiras. Será esse tratamento, e consequente conduta que traz implícita, realmente humanista? Será mesmo necessário afogar-nos nesse mar de burocracia? ${ }^{3}$

Em conversas com colegas de distintas universidades públicas, não me causou surpresa o fato de estes relatarem impedimentos ao trabalho de pesquisa e do estabelecimento de acordos internacionais provocados por situações similares às que descrevi. Acredito que esses dois episódios relatados exemplificam a grande diferença existente entre as posturas e procedimentos adotados nas IES brasileiras e estrangeiras. No Brasil há publicações de planos, metas e medidas com a finalidade de promover a internacionalização dos programas de pós-graduação. Todavia, as distinções severas entre os procedimentos administrativos devem ser levadas em conta quando se pensa a respeito da internacionalização, e é sobre isso que discorro a seguir.

Antes, esclareço que o objetivo deste artigo não é relatar empecilhos enfrentados pelos pesquisadores das IES brasileiras, mas intento refletir sobre os meandros da internacionalização tendo por base situações cotidianas reais. Para tanto, a metodologia adotada é a análise crítica de experiências de cooperações internacionais em confronto com documentos de área e planos de internacionalização lançados pela Capes e por algumas IES. Como a proposta é considerar a internacionalização sob uma abordagem humanista, o tópico a seguir oferece algumas das razões oferecidas pelas IES para investir na internacionalização, e, a seguir, defino o que entendo por humanismo no âmbito deste texto. O tópico seguinte contrapõe internacionalização e tradição. Adiante, apresento minha posição com respeito ao que denominei de expectativa de honestidade. Esses aportes nortearão as posteriores colocações sobre internacionalização, mas com o intuito de subverter a ordem em que essa tem sido tratada, ou seja, colocando o indivíduo como elemento principal desse processo, no lugar de instituições ou dos produtos e patentes gerados.

3 Embora essas duas situações gritantemente diferentes entre os procedimentos típicos das instituições brasileira e estrangeira sejam exemplos pessoais, em conversas com colegas de outras IES brasileiras, sejam estas estaduais ou federais, fiquei sabendo que as exigências burocráticas são, infelizmente, similares às da UnB. Prova maior desse excesso de burocracia é o próprio Plano de Internacionalização da UnB (2018), que aponta a desburocratização como um dos maiores desafios a serem superados. 


\section{Objetivos da Internacionalização}

A ideia de internacionalizar convida a indagar sobre os motivos, vantagens e desvantagens intrínsecas a esse processo. Em um documento lançado recentemente (UNB, 2018), a Universidade de Brasília aponta algumas justificativas para a internacionalização. Resumidamente, essas razões poderiam ser compreendidas sob um denominador comum: a urgência em formar cidadãos aptos para atuar em um mundo globalizado. A universidade, assim, admite e assume a responsabilidade de viabilizar o preparo de seus alunos e pesquisadores para participarem em uma sociedade multicultural, cujas fronteiras geográficas e culturais serão diluídas e, desse modo, os problemas decorrentes não serão mais problemas locais, mas, sim, globais ${ }^{4}$. Por conta disso, esses problemas deverão ser debatidos e resolvidos com a participação de toda a comunidade internacional, pois essas demandas afetarão a todos em escala mundial. $\mathrm{O}$ aspecto multicultural mencionado é relevante, pois, apesar de o contexto social contemporâneo ser entendido como globalizado, sobretudo como resultado da internet pervasiva e da acessibilidade possibilitada por outros meios de comunicação e de entretenimento, ainda existem diferenças significativas entre as diversas comunidades do planeta, que, por sua vez, possuem uma riqueza cultural de valor inestimável que pode ser compartilhada no diálogo intercultural promovido com as ações de internacionalização. Além disso, entendo como mais do que urgente o estímulo ao contato e ao convívio multicultural, pois no momento político delicado em que vivemos, no qual presidentes são eleitos com base em discursos separatistas e discriminatórios, é urgente pensar a internacionalização como maneira de fomentar o convívio e o aprendizado com a alteridade.

Artigos recentemente publicados sobre o tema da internacionalização, como o de Pedro Goergen (2012), por exemplo, propõem discutir conceitual e filosoficamente o papel da universidade como produtora de conhecimento no panorama de um mundo globalizado, questionando, por exemplo, os impactos da internacionalização sobre a cultura tradicional e a autonomia nacional. Ao lado das justificativas que visam ao preparo de alunos e docentes para atuarem em um mundo global e ao mesmo tempo multicultural, há autores que compreendem as razões da internacionalização sob um aspecto mais pragmático, focado na complementação da capacitação profissional (MARRARA, 2007). Há, também, autores que alertam sobre os interesses majoritariamente financeiros que alguns órgãos e instituições acabaram por impingir a esse processo. Isso acontece porque algumas universidades (sobretudo as estrangeiras), na esteira do processo mercantilista de comércio globalizado, concebem a educação como mercadoria, cobram pelos cursos e aumentam os lucros com os procedimentos de acolhimento de um pesquisador estrangeiro (tais como, a cobrança de altas taxas para a emissão de documentos para o visto e para o envio de cartas de aceitação). Prova maior dessa vergonhosa mercantilização do conhecimento são os preços cobrados por revistas científicas para a publicação e posterior disponibilização do acesso a artigos

4 Alguns estudiosos preferem chamar de glocal, isto é, os problemas locais que participam ou repercutem globalmente, ou vice-versa. 


\title{
científicos.
}

Também preocupada com o lado cruel da mercantilização da educação, a professora Ana Lúcia Almeida Gazzola ${ }^{5}$, às vésperas da Conferência Regional para Educação Superior, em Córdoba (2018), comentou a respeito da importância da integração das IES para fortalecer as universidades e de ações de cooperação para a pesquisa na América Latina:

\begin{abstract}
Espero que a CRES 2018 afirme a importância da integração regional, da internacionalização solidária, da mobilidade entre os vários sistemas como forma de fortalecer as instituições e as redes e, também, para nos permitir competir com vantagem de bloco com outros sistemas, outras regiões e outros grandes processos nesse mundo globalizado em que a cooperação é predatória e pouco solidária. (GAZZOLA, 2018).
\end{abstract}

Outra razão frequentemente apontada para investir na internacionalização é o fato de os programas brasileiros de pós-graduação visarem alcançar um estatuto de excelência acadêmica, que é atingido principalmente pela transformação de um programa nacional em internacional. Obviamente, um dos frutos colhidos nesse processo é a melhor avaliação do programa, levando a melhor classificação e, portanto, elevando o orçamento recebido do governo brasileiro6. Diversos planos de internacionalização publicados recentemente por universidades brasileiras indicam, dentre seus respectivos objetivos, a expectativa do aumento da nota dos programas de pós-graduação. $O$ texto desses distintos planos poderia ser resumido na citação retirada do plano de internacionalização da UFC, que indica 39 objetivos, para a pesquisa, educação e extensão a serem buscados com a internacionalização:

Promover a atualização e continuada qualificação dos programas de pós-graduação estabelecendo conjuntamente parâmetros e estratégias para a elevação do conceito tanto na avaliação da Capes no quesito de internacionalização quanto com respeito a critérios de excelência internacionais, segundo modelos de avaliação interna dos cursos de pós-graduação com base em comparativos internacionais. (UFC, 2017, p.7).

No bojo desse processo, espera-se logicamente o aumento do número de projetos de cooperação internacional entre as universidades brasileiras e estrangeiras, visando ao aumento da produção verificada na publicação de artigos. A esse respeito, vale mencionar que, dentre os critérios adotados pela Capes como indicadores do nível (ou estágio) de internacionalização das universidades, estão: “№ de Prof. visitantes e Pós-doutores estrangeiros; № de projetos de cooperação internacional; № de artigos publicados em revistas com JCR; № de artigos publicados com coautoria estrangeira" (CAPES, 2017b,

\footnotetext{
5 Ana Lúcia Almeida Gazzola é ex-diretora do Instituto Internacional para a Educação Superior na América Latina e o Caribe (UNESCO-IESALC), ex-reitora da Universidade Federal de Minas Gerais (UFMG) e ex-secretária estadual de Educação Básica do Estado de Minas Gerais.

6 Thiago Marrara, comenta a esse respeito: "No Brasil, [a internacionalização] assume relevância adicional para as IES, uma vez que a Capes a toma como condição para a concessão das notas máximas de avaliação no âmbito da pós-graduação. A obtenção dessas notas, por sua vez, amplia o reconhecimento das IES e do programa bem avaliado, além de lhes permitir o acesso a certos recursos financeiros, tais como os provenientes do Programa de Excelência Acadêmica (PROEX), exclusivos para programas com reconhecido nível de excelência" (MARRARA, 2007, p.256).
} 
p.18). No mesmo documento é considerado o fator de impacto das publicações de autores brasileiros publicando individualmente e em parceria com autores estrangeiros. O fator de impacto das publicações de brasileiros em coautoria com colaboradores internacionais aumenta consideravelmente. Como Portugal é um país muito procurado para realização de doutorados sanduíche e pós-doutorados, o documento adverte que, "ao confrontarmos o fator de impacto das publicações em parceria, vemos que Portugal fica aquém do desejado" (CAPES, 2017b, p.45). Em vista disso, o relatório aconselha as instituições de ensino a considerarem esse aspecto em seus planos de internacionalização, ou seja, investirem em cooperações com países onde as parcerias têm maior fator de impacto. Desse modo, percebe-se que, apesar dos discursos em prol de parâmetros qualitativos, as exigências quantitativas ainda dominam o rol de critérios para avaliação dos vários atores e setores da pesquisa acadêmica, tais como proponentes de projetos de pesquisa, programas de pós-graduação, planos de internacionalização etc. Para citar um exemplo, que é reiterado em diversos planos de internacionalização lançados nos últimos anos7, a Unoesc objetiva: "[...] incentivar publicações internacionais com relevante fator de impacto e em coautoria com autores estrangeiros" (UNOESC, s.d., p.6).

Curiosamente, há vinte anos, Angelo Pinto e Jailson Andrade alertavam para a conivência com essa mentalidade produtivista na pesquisa científica ao comentarem sobre o porquê da adoção do Fator de Impacto como instrumento para verificação da importância de um artigo científico. Consoantes aos problemas aqui apontados sobre o mercantilismo no processo de internacionalização, os autores comentavam que "publicações científicas vêm sendo, cada vez mais, um produto de mercado, tendendo, cada vez menos, a atender a propósitos científicos. Basta ver o número de revistas científicas que vêm sendo lançadas todos os anos, e o preço das assinaturas de algumas revistas" (PINTO; ANDRADE, 1999, p.451). Nesse mesmo artigo os autores expõem suas opiniões do porquê se deve ter cuidado na aplicação do fator de impacto. São várias suas advertências, bem como as de tantos outros pesquisadores internacionais que explicam as limitações desse critério. O que me chama mais a atenção nessa discussão é que esse critério só quantifica citações em periódicos indexados. Em vista disso, a publicação de um livro não teria qualquer impacto. De acordo com o critério "fator de impacto", um livro como o de Leonard Meyer (Emotion and Meaning in Music) não seria sequer considerado pelo JCR (Journal of Citations Report). E, obviamente, essa situação não corresponde à realidade, pois a obra de Meyer é o que eu classificaria como realmente de impacto, pois vem servindo como fundamentação teórica para milhares de pesquisas, a ponto de se tornar um verdadeiro best-seller da área da Música, pois foi lançada em 1956 e ainda continua sendo reimpressa. No entanto, é difícil lutar contra mais essa forma de colonialismo, e o fator de impacto é cada vez mais utilizado pelas instituições de fomento à pesquisa para ranquear e selecionar projetos, como é possível observar no próprio documento da Capes (2017b).

Buscando fornecer outra vertente para se pensar a internacionalização da pós- graduação brasileira, proponho apresentar uma reflexão a partir de dentro de algumas

7 Ver também UFSC, 2018, p.7. 
ações de cooperação internacional. Sobre esse aspecto particular da apresentação e análise de dados coletados em projetos de pesquisa por mim coordenados, ressalto que, embora alguns avaliadores não considerem como justificada a fundamentação de artigos em experiências pessoais, a própria Capes tem como critério de ranqueamento das propostas de projetos de internacionalização "a capacidade técnica, liderança e experiência internacional acadêmica dos membros do grupo gestor do projeto" (Edital Capes-PrInt, 2017a, subitem 9.2.2.1, p.13). Portanto, no meu entender, é justamente a experiência adquirida com a prática da pesquisa, ou seja, com a execução de um projeto, que torna o pesquisador mais ciente e preparado para resolver as diversas situações e contingências, fornecendo-lhe habilidade para lidar com o inusitado. Além disso, é a experiência que viabiliza a abordagem analítica a partir de dentro do processo de colaboração internacional.

Em vista do exposto, reforço que meu objetivo é refletir sobre os meandros da internacionalização, tendo como base os resultados obtidos em três projetos de parcerias internacionais. Pretendo interrogar formas e modelos geralmente adotados pelas instituições de ensino e pesquisa, ponderando, contudo, sobre os resultados esperados. Essa ponderação sobre as realizações advindas e/ou conseguidas com projetos será considerada a partir de uma perspectiva humanista, definida a seguir.

\section{Nota sobre o humanismo}

Vale esclarecer que, por humanista, eu quero estabelecer conexão direta com o campo de estudos denominado Humanismo, definido como o potencial estudo do ser humano, visando ao desenvolvimento de seu caráter, sensibilidade e potencialidades criadoras. Humanismo, portanto, aqui não se referirá à corrente literária surgida na transição entre Idade Média e Renascença (período chamado de Quattrocento, na Itália) ou ao conjunto de temas e disciplinas que seriam necessários para edificar uma "educação clássica" (segundo a concepção de Georg Voigt ${ }^{8}$, que, em 1859, estabeleceu definitivamente essa acepção para a palavra "humanismo". Ver GIUSTINIANI, 1985, p.172). Na Idade Média, humanus era usado para diferenciar aquilo que não era divino, estabelecendo, assim, a distinção entre Deus e homem. Durante a Renascença, essa distinção foi mantida justamente para marcar a mudança de concepção filosófica do teocentrismo para o antropocentrismo, este que se assomava na esteira das recentes descobertas científicas, especialmente o heliocentrismo. O humanismo filosófico também se fia nesta acepção do termo ${ }^{9}$, ou seja, humanus como o conjunto de atributos e características pertencentes ao homem. De forma similar, diversas palavras são formadas pela adição do sufixo "ismo", palavras estas que indicam justamente agrupamento, coletivo,

\footnotetext{
8 Die Wiederbelebung des classischen Alterthums, oder das erste Jahrhundert des Humanismus. Traduzido ao inglês como: The Revival of Classical Antiquity, or the first century of Humanism. Segundo Patrick Baker (2015, p.6), a tradução ao italiano ganhou relevância por haver inspirado o humanismo clássico nos países de línguas latinas: II Risorgimento dell'antichità classica, ovvero il primo secolo d'Umanesimo (Tradução de D. Valbusa, com notas e edição de Eugenio Garin).

9 Um dos significados de humanismo mais em voga desde o final da Idade Média até o final da Renascença é a de erudito. Assim, humanista referia-se a uma pessoa culta, douta, literata (GIUSTINIANI, 1985, passim).
} 
coletânea, por exemplo, socialismo (conjunto de características do que pertence ao social); marxismo (princípios e ideias próprias do pensamento de Karl Marx); minimalismo (conjunto de posturas estéticas associadas à minimal art). O sentido de educação humanista foi estabelecido na Renascença, embora fundamentado em concepções da antiguidade grega clássica (CARVALHO, 2015). O humanismo filosófico, por sua vez, viria a se estabelecer durante o Iluminismo, especialmente na França. "'Humanismo' como um termo filosófico parece ter surgido primeiro na França na segunda metade do século XVIII" (GIUSTINIANI, 1985, p.175) ${ }^{10}$. Giustiniani entende que o humanismo ganhou consistência filosófica na esteira da ideologia marxista. Segundo o autor, "na visão marxista, humanismo é a realização e perfeição humana, equivalente à felicidade, a aspiração natural de todos que são impedidos de atingi-la pela necessidade econômica e pela exploração dos trabalhadores, os males inerentes a todas as sociedades desde seu início" (GIUSTINIANI, 1985, p.176)11. Percebe-se que o humanismo, no âmbito da doutrina marxista, está atrelado ao desenvolvimento moral de toda a sociedade. Uma vez que a felicidade seria a condição aspirada por todos, esta, por sua vez, não seria dada desde cima, mas seria atingida na observância de uma conduta igualitária, ou seja, ética (veja adiante).

O sentido do humanismo ligado ao resgate dos valores clássicos tem também servido como mote para considerações relevantes da contemporaneidade, implicando em uma educação humanista. Trata-se, portanto, de uma concepção de educação que não visa somente ao preparo de pessoas para exercerem determinada profissão, mas uma educação que objetiva a formação integral do cidadão, preparado para pensar criticamente e participar das variadas esferas da sociedade e refletir sobre a pluralidade de assuntos que se lhe apresentem. Observa-se, assim, que a educação adquire um papel político e não somente instrumental. Essas são considerações realizadas por José Sergio de Carvalho, que apresenta como hipótese para a crise na educação escolar justamente "o esvanecimento do sentido político e existencial da experiência escolar" (CARVALHO, 2017, p.1025).

Há outros autores que fazem da abordagem humanista a base de suas reflexões sobre temas variados - embora prefiram usar o termo humanitário ou humanizador. No Brasil esse pensamento estabeleceu-se definitivamente com Paulo Freire e desdobrou-se nas pesquisas e ações pedagógicas de seus estudiosos. Para citar um exemplo, Heloisa Feichas, tendo por fundamentação a vasta literatura de Paulo Freire, além de oferecer cursos, tem escrito refletindo sobre o significado de uma educação musical humanizadora no desenvolvimento de uma espiritualidade crítica. Feichas ressalta a importância das relações interpessoais e apresenta práticas musicais colaborativas como situações privilegiadas para o desenvolvimento dessas relações inter e intrapessoais, inspirando criticidade, benevolência e autossuperação (ver, por exemplo, FEICHAS, 2019. Sobre humanismo e educação, ver também OLIVEIRA, 2014; JOLY; SEVERINO, 2016).

10 Texto original: 'Humanism' as a philosophical term seems to have appeared first in France in the second half of the eighteenth century.

11 Texto original: In the Marxist view, humanism is human fulfillment and perfection, tantamount to happiness, the natural aspiration of all who are thwarted from achieving it by economic need and workers' exploitation, the inherent evils of all societies from their beginnings. 
Interessante notar a consonância desses entendimentos com diversos setores da academia. O plano de internacionalização da Universidade Federal do Ceará, por exemplo, já em sua primeira página, atesta: “É consensual que a busca de soluções comuns para graves ameaças à viabilidade futura da civilização requer o fortalecimento do consórcio científico e humanístico, sendo as universidades internacionais o ambiente mais favorável para essa integração" (UFC, 2017, p.1). Por fim, no âmbito da abordagem humanista aqui sugerida, os resultados dos projetos de pesquisa realizados não são aferidos apenas na contagem dos produtos gerados, pois os saldos e consequências interpessoais, associados aos estímulos e inspirações criativas propiciadas, ganham em dimensão quando contrapostos à também desejada produção de artigos, artefatos, marcas e patentes.

\section{Padrão ou padronização internacional? ${ }^{12}$}

Embora a ideia de modernização do país possa sugerir, entre outros, a produção de ferramentas e novas tecnologias, maquinários, softwares, medicamentos e registro de patentes, o campo das humanidades, em geral, e o da educação, em específico, obviamente também participam, dentre outras possibilidades, aperfeiçoando e transformando métodos e processos e criando novas pedagogias. Pedro Goergen focou suas considerações justamente nesse setor e analisou detalhadamente as relações entre a economia globalizada e a produção de conhecimento. Na sua visão, "a economia internacionalizada e o desenvolvimento científico/cultural se condicionam mutuamente a ponto de se tornar difícil falar em autonomia da ciência" (GOERGEN, 2012, p.249). Avanços científicos precisam de investimento financeiro e de pessoal, o mesmo ocorre com inovações no campo da cultura (o mecenato não é um procedimento novo). Todavia, essa parceria entre investidor e criador passa a ser problemática quando o primeiro cerceia ou impõe determinações sobre o segundo. Essa situação, embora ocorra em todos os ramos da pesquisa, é mais comum nas ciências empíricas, uma vez que as companhias escolhem subvencionar aquilo que entendem como potencial fonte de lucro. Em seu exame dos possíveis desdobramentos trazidos para a educação no bojo do processo de internacionalização, Goergen toma como exemplo a padronização do sistema europeu de ensino consolidada por meio da Declaração de Bologna. Esse processo, iminentemente motivado por interesses econômicos, promoveu uma reforma no sistema educacional europeu em acordo com modelos internacionais, o que de certa forma subtraiu e desvinculou do ensino superior características tradicionais de cada nação envolvida. Para o autor, "a necessidade de se adaptar aos rumos ditados internacionalmente justificava e continua justificando sacrificar uma rica e multissecular cultura e tradição acadêmicas dos países europeus" (GOERGEN, 2012, p.250).

Considero exemplar a análise de Goergen, pois são atitudes padronizadoras como aquelas por ele expostas que revelam o lado perigoso da chamada globalização. Há que 
se tomar especial cuidado para que o processo de internacionalização não descambe para a mera importação de produtos e metodologias criados no exterior, como é o caso da adoção do fator de impacto como critério de avaliação. Nem sempre o internacional é sinônimo de melhor, e, com relação à adoção dos métodos, deve-se buscar o mais adequado à realidade sociocultural de cada país. A esse respeito, Pinto e Andrade apontam mais uma das limitações do fator de impacto ao esclarecerem que "algumas pesquisas são de caráter mais regional do que outras, mas nem por isso menos importantes para a Sociedade na qual estão inseridas. Este é o caso, por exemplo, da Saúde Pública, Ecologia, Botânica, Geologia, Agronomia etc." (PINTO; ANDRADE, 1999, p.451).

O relatório da Capes (2017b, p.13) explicita a média da relação entre o número de solicitações das distintas modalidades de bolsa e os países para os quais essas bolsas são solicitadas. Observa-se a predominância de solicitações para os Estados Unidos, Canadá e os países da Europa, ou seja, os destinos mais desejados são os países desenvolvidos. Esse fato pode enfraquecer a possibilidade de colaborações com países que, embora sejam entendidos como menos desenvolvidos, possuam know-how em determinada área do conhecimento (tal como a Medicina em Cuba, por exemplo). A respeito, Gazzola comenta:

É preciso que existam acordos de cooperação e parcerias com colegas dos países desenvolvidos, mas também precisam ser feitos entre nós [América Latina e Caribe]. Não só para diminuir as assimetrias regionais, mas também as assimetrias intrarregionais. Nós não podemos cair em uma lógica do salve-se quem puder. Eu luto pelos meus financiamentos e os outros que não tenham nada. Isso não vai desenvolver a ciência nacional de nossos países, não vai promover o desenvolvimento tecnológico de cada nação. (GAZZOLA, 2018).

O relatório da Capes aponta também o ainda incipiente interesse das IES brasileiras na mobilidade acadêmica e no estabelecimento de acordos com países do Brics. Segundo o relatório, "a China foi o único país citado dentro do grupo Brics (cinco principais economias nacionais emergentes, que inclui Brasil, Rússia, Índia, China e África do Sul), sendo que a maior parte dos países citados se encontra na Europa" (CAPES, 2017b, p.20). Entendo que a constatação apontada no relatório da Capes do interesse em colaborações com a China se deve justamente ao fato de esse país ser o mais rico dentre os demais do Brics. Ressalvo que o plano de internacionalização da UFSC foi o único a explicitar o interesse em cooperações no âmbito do Brics (UFSC, 2018, p.20).

Esses indicativos podem levar ao equivocado entendimento de que o patamar de excelência acadêmica é atingido por meio das cooperações estabelecidas com centros de pesquisa dos países desenvolvidos. A chamada excelência acadêmica deve ser conquistada com a própria pesquisa e por meio da interação do pesquisador com seus colaboradores e interlocutores - sejam estes nacionais ou estrangeiros -, pois excelência não pode ser entendida como um produto final do processo de internacionalização, tampouco avaliada por critérios exclusivamente quantitativos, tais como o fator de impacto. Prova disso é o que esclarecem Pinto e Andrade (1999, p.451): "Os artigos com erros conceituais ou com erros na interpretação dos resultados experimentais são 
muito citados por serem contestados cientificamente". Percebe-se, assim, a inverdade oculta no cômputo do número de citações como critério para aferir a excelência de um artigo. Em resumo, a experiência internacional é mais uma fase na busca da chamada excelência acadêmica, e não um fim em si mesma. A mera adesão a um padrão específico de interesse internacional não deve sobrepujar ou eliminar a pluralidade dos processos científicos locais, uma vez que diferentes realidades culturais demandam distintos modelos e métodos.

Nesse sentido, cooperações internacionais têm o poder de promover e intensificar reflexões sobre aspectos culturais, abrindo novas possibilidades de renovação pessoal, em vista das contingências e situações enfrentadas no exterior pelos sujeitos envolvidos. Isso se dá porque um outro ambiente cultural pode transformar a pessoa e prover um novo olhar a respeito de sua própria cultura, conduzindo a um repensar de seus costumes e procedimentos, o que pode resultar em atitudes criativas. Outras metodologias e estratégias podem surgir do contato com um contexto cultural distinto, levando o pesquisador a adaptar, refletir ou transformar suas convicções em razão de contingências físicas e psicológicas. Estar em outro país pode ser um jeito rápido para conseguir respostas para situações culturais diferenciadas, pois existem questões de método que são mais bem compreendidas quando vivenciadas e apreendidas in loco. Isso pode funcionar como estímulo à criatividade e, também, como alavanca para uma mudança de comportamento, o que ao fim pode promover um repensar ético (veja a seguir). Embora difícil de quantificar, esse lado subjetivo da mobilidade acadêmica não deve ser ignorado.

\section{Expectativa de honestidade}

No âmbito da perspectiva humanista aqui exposta, as mudanças de comportamento em direção a uma nova ética são desejadas e apreciadas após uma experiência no exterior. Eu, felizmente, tive a possibilidade de testemunhar essas modificações. Após o período de intercâmbio, imersos na cultura sueca, os alunos que participaram do intercâmbio assimilaram e trouxeram de volta ao Brasil vestígios comportamentais que valorizaram em suas experiências naquele país. Nesse sentido, certos tipos de mudança de conduta nos estudantes brasileiros puderam ser observados, incluindo aspectos básicos, como chegarem às aulas pontualmente, submeterem trabalhos dentro dos prazos, serem mais organizados no planejamento de vários aspectos de sua vida acadêmica, e até mudanças mais profundas, como, por exemplo, repreenderem colegas que agiam de modo antiético.

Ética, no âmbito deste artigo, é entendida na sua acepção ampla como o ramo da filosofia que objetiva refletir sobre a essência dos princípios, valores e questões fundamentais da moral, tendo como base as normas consideradas universalmente válidas para nortear o comportamento humano e a conduta de um indivíduo ou de uma sociedade. Observa-se que a moral é variável histórica e culturalmente, isto é, comportamentos que para um grupo cultural podem ser aceitáveis não serão para outra comunidade. 0 mesmo vale para os diferentes períodos da história. Na Idade Média, a igreja entendia 
as execuções empreendidas durante a inquisição como aceitáveis, atualmente esse tipo de atitude é reprovável. Todavia, quando amparada por princípios éticos, as questões morais podem ser debatidas sob um denominador comum.

Há diversos e importantes textos de filósofos que discorreram sobre a ética de acordo com seu contexto. Aristóteles escreveu quatro tratados: a Ética a Nicômaco, Ética a Eudemo, Das virtudes e vícios e a Magna Moralia. O conjunto desses textos aponta para um denominador comum, a eudaimonia (ARISTÓTELES, 1991). Segundo Aristóteles, todas as nossas ações são teleológicas, e esse objetivo prático-racional é o bem supremo atingido pela virtude. Assim, a finalidade de tornar-se uma pessoa virtuosa é a eudaimonia, ou seja, a felicidade. $\mathrm{O}$ arcabouço do pensamento ético aristotélico também pode ser entendido como tendo um objetivo político, ou seja, regular a conduta do cidadão na pólis. O que leva a postular uma orientação ética para além do (ou maior que o) indivíduo, ou seja, uma moral maior ou magna moralia. Na antípoda desse entendimento apresenta-se a mínima moralia de Adorno (1951), que tem como ponto de partida o indivíduo, ou, dito de modo mais preciso: a experiência subjetiva. No lugar de discutir a ética com o fim orientado à prescrição de normas de boa conduta no âmbito da esfera pública da sociedade pós-industrial capitalista, Adorno reprova a ideia de um indivíduo diluído na sociedade consumista e propõe, em sua minima moralia, resgatar o subjetivo para o primeiro plano.

As esferas subjetiva (do indivíduo) e pública (indivíduo em sociedade) estão relacionadas, e a integração entre esses domínios éticos foi explicada brilhantemente pelo neurocientista Antonio Damásio (2003), que parte da biologia do sujeito e a estende ao orbe do social. Damásio (2003, p.198) é exemplarmente claro:

Os contratos sociais e políticos são extensões do mandato biológico pessoal. Somos estruturados biologicamente e, de uma certa forma, inclinados a sobreviver agradavelmente em vez de sobreviver com dor, e dessa necessidade provém uma certa forma de contrato social, e é curioso pensar que a tendência natural da procura de concordância social foi incorporada nas nossas características biológicas, pelo menos em parte, devido ao sucesso evolucionário das populações cujos cérebros aperfeiçoaram os comportamentos cooperativos.

Nessa perspectiva, a evolução da espécie leva em consideração não somente os fatores de adaptação ao habitat físico-geográfico, mas também considera como melhor adaptada a espécie que consegue criar uma condição de vida melhor que o mínimo aceitável, ou, nas palavras de Damásio, "melhor que o neutro". A busca pelo bem-estar do indivíduo, e consequentemente da espécie, seria impulsionada por sentimentos de prazer, pois o sentimento de dor é indesejável em um corpo-mente saudável. Assim, é possível postular uma interação entre a mínima e a máxima moralia. Desse modo, a eudaimonia aristotélica atenderia a um princípio biológico prévio, ou seja, a vida sem dor, e transbordaria para o plano social objetivando o bem-estar e a felicidade do indivíduo vivendo em comunidade.

Tratar de questões éticas em um artigo sobre internacionalização pode soar dissonante; porém, justamente em razão de as discussões sobre ética serem inevitavelmen- 
te contextuais ${ }^{13}$, entendo as considerações éticas não somente como pertinentes, mas necessárias.

É difícil explicar algumas características que estão enraizadas na cultura brasileira, e uma dessas características (que é mesmo destacada como estratégia de sobrevivência do brasileiro) é a malandragem ou, dito de outro nome, a tendência a agir de modo não ético. No Brasil, a percepção de corrupção é grande ${ }^{14}$. Corrupção não deve ser entendida simplesmente como o recebimento ou pagamento de suborno (tão comum nos noticiários sobre os políticos do Brasil), mas como o uso de quaisquer meios ilícitos (ou seja, contrários à moral) para obtenção de benefícios ou favorecimentos para si ou para terceiros. Quando digo que a explicação é difícil, é porque todos nós somos, em princípio, contra a corrupção. No entanto, o problema não é tão simples quanto pode parecer. Ao longo da história brasileira, fomos expostos a um sem-número de maus exemplos praticados por pessoas que supostamente deveriam servir como cânones de atitude ética. Essas pessoas são juízes, políticos, advogados, policiais, religiosos, reitores, empresários, professores, médicos, celebridades, dentre tantos outros de uma lista inumerável. Meu ponto é: as pessoas que deveriam vigiar e garantir a conduta ética são, frequentemente, expostas como desonestas. Presenciar esses maus exemplos diariamente, e por muito tempo, tem impactado a sociedade brasileira a ponto de as pessoas passarem a considerar "normais" certos tipos de comportamento, como subornar um guarda de trânsito para escapar de uma multa ou comprar ingressos de cambistas, por exemplo. Quando a corrupção se espalha para todas as esferas da sociedade e se torna cultural, as mudanças éticas são muito difíceis. No Brasil, pagamos elevada carga tributária, sem, no entanto, receber o retorno dessas contribuições fiscais na forma de serviços sociais de qualidade. O dinheiro dos impostos é usado para a manutenção de uma estrutura milenar de poder e servidão, na qual um número limitado de pessoas e de corporações tem o controle da massa populacional. Por causa dessa condição, as pessoas desenvolvem artifícios de evasão fiscal e buscam tirar proveito de qualquer situação, mesmo à custa de seus semelhantes. Vivemos em um estado de coisas em que a honestidade não é esperada, e, justamente por conta da falta de expectativa de honestidade, a burocracia no Brasil é gigantesca. A burocracia em todos os setores da esfera pública é a forma (ineficaz, no meu entender) de tentar evitar as práticas fraudulentas.

Penso que é precisamente em relação a esse tipo de situação que a experiência internacional pode contribuir para motivar uma mudança ética. Estar em um contexto oposto ao brasileiro faz com que se experimente os benefícios de se viver em uma sociedade mais igualitária, sem estar constantemente preocupado em ser lesado, pelo governo ou pelas pessoas ao redor, porque a honestidade é a postura esperada de qualquer pessoa - como fica evidente no exemplo comentado na introdução desse texto.

13 Veja-se, por exemplo, o fato de que alguns países consideram aceitável o sacrifício de animais com finalidade científica. Há outros países que rejeitam essa atitude, classificando-a como anti-ética.

14 Indicadores e estatísticas da percepção de corrupção ao redor do planeta podem ser confrontados em: https://ipc2018.transparenciainternacional.org.br/\#ipc-2018. 
Nos últimos seis anos, tive a oportunidade de coordenar dois projetos envolvendo as universidades de Brasília e de Örebro, na Suécia. Um desses projetos ocorreu ao nível da graduação, financiado integralmente pela Fundação Linnaeus-Palme, e promoveu o intercâmbio de 21 estudantes e de 23 docentes (brasileiros e suecos). O outro projeto deu-se ao nível da pós-graduação e foi subvencionado pelas agências Capes e outra fundação sueca: STINT - Stiftelsen for Internationalisering av Högre Utbildning och Forskning (Fundação Sueca para Cooperação Internacional e Pesquisa em Educação Superior) e fomentou missões de estudo e de trabalho para 13 pesquisadores brasileiros e suecos. Um dos aspectos que me assomaram durante a realização desses projetos está ligado aos resultados atingidos. Normalmente, espera-se que uma pesquisa gere produtos, sejam estes de natureza física (aparelhos, gadgets, CDs etc.) ou intelectual (publicações). Essa expectativa pode ser atestada na leitura dos objetivos dos Planos de Internacionalização das IES. No entanto, quando conversei com alunos e professores regressados do período de intercâmbio querendo saber como a experiência naquele país os tinha impactado, esperava que enfatizassem sua própria melhoria e desenvolvimento técnico, ou seja, o aumento de suas habilidades nos respectivos instrumentos. Todavia, após o período de permanência na universidade estrangeira, os aspectos interpessoais foram sempre os mais citados, sendo considerados como altamente positivos pela totalidade dos discentes e docentes. Decidi oficializar essas percepções e pedi aos professores e alunos que respondessem a um questionário com respostas abertas. Como eu esperava, intercambistas e docentes brasileiros, ao regressarem do exterior, apresentaram como um dos pontos altos do programa a infraestrutura e a organização da universidade internacional. Por outro lado, brasileiros e suecos, quando consultados a respeito do que consideravam como o aspecto mais significativo da experiência internacional, forneceram respostas espontâneas e quase unânimes, elegendo o estabelecimento de novos laços afetivos como a característica mais relevante do projeto. Porém, esse aspecto nunca fez parte do planejamento do projeto e me fez pensar que o objetivado como resultado de uma pesquisa pode ser imponderável.

\section{Considerações finais}

A internacionalização dos programas de pós-graduação, por meio do estabelecimento de colaborações com instituições estrangeiras, certamente viabiliza a capacitação do pesquisador por meio de sua inserção no desenvolvimento de novas tecnologias, bem como da assimilação e disseminação destas. Por outro lado, o encontro com um contexto cultural diferente também possibilita o crescimento pessoal; porém, considerado não exclusivamente do ponto de vista profissional, em sua faceta ligada à habilidade técnica, mas, antes, sob a perspectiva da formação do caráter do sujeito envolvido. Isso ocorre pelo fato de a vivência em uma outra cultura favorecer a criação de novas relações interpessoais, gerando, assim, um amadurecimento pessoal e uma transformação ética. 
A mobilidade discente e docente gera o choque cultural e revela as deficiências internas da instituição nacional a qual pertencem. Por exemplo, todos os intercambistas e pesquisadores que entrevistei declararam terem se surpreendido com a infraestrutura, organização, agilidade, diligência e falta de burocracia observadas na instituição internacional em comparação ao que ocorre nas instituições brasileiras. Neste sentido, a experiência no exterior trouxe como "resultado" a tomada de consciência dos aspectos deficitários da universidade brasileira que necessitam mudanças e adequações urgentes.

Todos os planos de internacionalização consultados reforçam a necessidade e objetivam implantar e/ou aprimorar a mobilidade acadêmica em todos os setores da universidade. O plano de desenvolvimento institucional da UFRGS, por exemplo, especifica:

No nível das ações, o PDI aponta para o aumento da mobilidade de todos os segmentos, o caráter multilinguístico das ações da Universidade, o desenvolvimento de uma política de atração e integração institucional de professores visitantes, pesquisadores visitantes e pós-doutorandos, o reforço das ações de acolhimento de parceiros acadêmicos, e o incentivo à criação de programas internacionais de pós-graduação com possibilidade de expansão dos acordos de formação conjunta (cotutela e joint degree) e dupla diplomação. (UFRGS, 2017, p.2).

Todavia, esse objetivo pode não ser tão simples de ser atingido em razão da burocracia a que as IES estão sujeitas. Um dos problemas com os quais convivemos e que dificultam (ou inviabilizam) a vinda de professores visitantes estrangeiros é a exigência da revalidação do diploma de doutorado emitido por universidades estrangeiras. Esse fato me soa como uma contradição em si mesma, pois se as IES querem atrair professores estrangeiros, obviamente sabem que estes possuem diplomas emitidos por universidades estrangeiras. Então, por que exigir que este documento seja revalidado no Brasil? Por mais que a plataforma Carolina Bori tenha sido criada com a intenção de facilitar processos de revalidação e reconhecimento de diplomas emitidos por IES internacionais, o processo é burocratizado e moroso. Mais uma vez estamos diante do caso da falta de expectativa de honestidade, pois a administração pública brasileira parece antever ações fraudulentas dos professores estrangeiros e demandam, então, a validação de seus documentos por algum órgão público do Brasil. Um professor pode ser reconhecido por toda a comunidade de pares internacionais. Porém, no Brasil, seu reconhecimento só é confirmado após passar pelo trâmite burocrático.

Entendo que aportes como os aqui descritos podem ser interpretados como problemas adicionais à discussão sobre a internacionalização, na medida em que lidam com facetas subjetivas, não quantificáveis, desse processo. No entanto, fazendo eco ao entendimento de Goergen (2012, p.249), acredito que "o conhecimento e a educação devem ter sempre um sentido de humanização, democratização e mudança social". E é justamente acolhendo os fatores humanos que o lado negativo da internacionalização poderá ser evitado, isto é, a sua vertente mercantilista, distante do intuito de investir 
no desenvolvimento científico e cultural e prioritariamente atrelada à busca de consumidores da educação. As considerações subjetivas, ao colocarem o desenvolvimento individual no primeiro plano, oferecem bases para viabilizar estratégias com o intuito de nos precavermos contra a perda da identidade, tradição e autonomia nacional. Previne, também, a mera importação de metodologias, por vezes alheias ao nosso contexto cultural e contra o clientelismo às instituições estrangeiras.

A internacionalização, à medida que promove a mobilidade de estudantes e pesquisadores, envolve os artifícios e estratégias viabilizadores de procedimentos de raciocínio diferenciado. Trata-se, por exemplo, de gerar novos e distintos "olhares" sobre os problemas. $O$ aparato cognitivo humano envolve as formas e os meios pelos quais nos damos conta da realidade, bem como a maneira como interpretamos o mundo. É preciso lembrar que não somente o cérebro está envolvido nesse mecanismo de formatação, significação e compreensão da realidade, mas também o corpo como um todo age como mediador e viabiliza a percepção de estímulos e informações do meio. A partir dessa rede cognitiva, formamos nossa compreensão das coisas e criamos conceitos e constructos que levam a explicar os fenômenos observados. Toda essa estrutura perceptiva e intelectiva fundamenta a criatividade humana, que poderá, naturalmente, ser desenvolvida ou atrofiada. De toda essa situação, é possível perceber a importância fundamental que o meio, o contexto no qual nos inserimos, exerce na consolidação da aprendizagem e do conhecimento. E é justamente por conta desse papel relevante que o fato de vivenciar in loco uma cultura diferente pode promover contingências que permitirão aos indivíduos envolvidos abertura perceptual, isto é, olhares renovados sobre antigas questões, levando a ações inovadoras e criativas. A oportunidade de enfrentamento cultural revela aspectos subjetivos importantes, porém normalmente negligenciados por serem difíceis de quantificar ou por não gerarem produtos físicos observáveis.

Acredito que experiências internacionais podem contribuir para o repensar de atitudes e procedimentos em voga nas instituições nacionais, revelando problemas pontuais e crônicos que necessitam soluções rápidas se de fato tem-se a intenção de participar plenamente do processo de internacionalização.

O relatório da Capes explicita que "a internacionalização das IES tem o potencial de transformar as vidas de estudantes e tem um papel cada vez maior para a ciência através da intensa troca de conhecimento acadêmico, permitindo assim a construção de capacidades sociais e econômicas" (CAPES, 2017b, p.4). Consoante a esse entendimento, percebo que, sob a perspectiva humanista aqui defendida, vale a pena notar as transformações observadas ao nível pessoal, como destacado em meu ponto sobre a expectativa de honestidade. Qualquer um que tenha vivido toda a sua vida dentro de um único contexto carecerá de perspectivas, o que significa que tenderá a considerar o estado de coisas em que viveu como sua única possibilidade de compreensão e ação na realidade cotidiana. Nesse sentido, passar algum tempo no exterior, enfrentar diferentes situações, ter contato com diversas pessoas, culturas e condutas proporcionará novos horizontes e enriquecerá a experiência humana. Essa mudança de perspectiva 
mostrará modos distintos para lidar com problemas semelhantes, além de estimular a criatividade. Estratégias como essas podem ajudar a preencher a lacuna entre a sociedade e a universidade, porque a educação é a maneira de levar dignidade às pessoas, e a dignidade é mais importante que a riqueza.

\section{Agradecimento}

Capes - Coordenação de Aperfeiçoamento de Pessoal de Nível Superior Fundación Carolina, Grupo Tordesillas, Espanha.

\section{Referências}

ADORNO, Theodor. Minima Moralia. Tradução de Artur Morão. Lisboa: Edições 70, 1951.

ARISTÓLES. Ética a Nicômano. Tradução de Leonel Vallandro e Gerd Bornheim. São Paulo: Nova Cultural, 1991. Disponível em: https://abdet.com.br/site/wp-content/ uploads/2014/12/\%C3\%89tica-a-Nic\%C3\%B4maco.pdf.

BAKER, Patrick. Italian Renaissance Humanismin the Mirror. Cambridge: Cambridge University Press, 2015.

CAPES. Programa Institucional de Internacionalização Capes-Prlnt. Edital n 41/2017. Brasília: Capes, 2017a. Disponível em: http://www.capes.gov.br/images/stories/ download/editais/10112017-Edital-41-2017-Internacionalizacao-PrInt-2.pdf.

CAPES. A internacionalização na Universidade Brasileira: resultados do questionário aplicado pela Capes. Brasília: Capes, 2017b. Disponível em: https://www.capes.gov.br/ images/stories/download/diversos/A-internacionalizacao-nas-IES-brasileiras.pdf.

CARVALHO, José Sérgio Fonseca de. Os ideais da formação humanista e o sentido da experiência escolar. Educação e Pesquisa, São Paulo, v. 43, n. 4, p. 1023-1034, 2017.

CORRÊA, Antenor Ferreira. A Humanist Perspective Within Higher Education Internationalization Process. In: Music in an Intercultural Perspective. Brasília: Strong Edições, 2016. p. 85-92.

DAMÁSIO, António. Ao encontro de Espinosa: as emoções sociais e a neurologia do sentir. Lisboa: Publicações Europa-América, 2003.

FEICHAS, Heloisa. Espiritualidade crítica: desenvolvendo alguns conceitos para uma educação musical humanizadora. In: CORRÊA, Antenor Ferreira; NARITA, Flávia M. 
Ensino e pesquisa em Artes: experiências no âmbito do ProfArtes. Goiânia: Ed. UFG, 2019. (no prelo).

GAZZOLA, Ana Lucia. Entrevista publicada no site do Instituto Internacional para la Educación Superior en América Latina y el Caribe (IESALC/Unesco), 2018. Disponível em: http://www.iesalc.unesco.org/2018/06/08/ana-lucia-gazzola-a-cres-2018-deveressignificar-os-principios-que-orientaram-a-reforma-universitaria/.

GIUSTINIANI, Vito R. Homo, Humanus, and the meanings of "humanism". Journal of the History of Ideas, v. 46, n. 2, p.167-195, 1985.

GOERGEN, Pedro. A internacionalização dos programas de pós-graduação. REP - Revista Espaço Pedagógico, Passo Fundo, v. 19, n. 2, p. 247-257, jul./dez. 2012. Disponível em: http://www.upf.br/seer/index.php/rep/article/view/3111/2125.

JOLY, Ilza Z. L.; SEVERINO, Natália B. (Orgs.). Processos educativos e práticas sociais em Música: um olhar para educação humanizadora - pesquisas em educação musical. Curitiba: CRV, 2016.

MARRARA, Thiago. Internacionalização da Pós-Graduação: objetivos, formas e avaliação. Revista Brasileira de Pós-graduação, v. 4, n. 8, p.245-262, 2007. Disponível em: http://ojs.rbpg.capes.gov.br/index.php/rbpg/article/view/132/126.

OLIVEIRA, Pedro Augusto Dutra de. Por uma educação musical humanizadora: o ensino coletivo de música a várias mãos. 2014. 136 f. Dissertação (Mestrado em Ciências Humanas) - Universidade Federal de São Carlos, São Carlos, 2014.

PINTO, Angelo C.; ANDRADE, Jailson B. de. Fator de Impacto de Revistas Científicas: qual o significado deste parâmetro? Química Nova, v. 22, n. 3, p. 448-453, 1999.

UFC. Plano de Internacionalização da Universidade Federal do Ceará. Fortaleza: PróReitoria de Relações Internacionais, Universidade Federal do Ceará, 2017. Disponível em: http://www.ufc.br/images/_files/a_universidade/plano-internacionalizacao-ufc/ plano-internacionalizacao-ufc.pdf.

UFRGS. Plano Institucional de Internacionalização da Universidade Federal do Rio Grande do Sul. Porto Alegre: UFRGS, 2017. Disponível em: http://www.ufrgs.br/propg/ print-ufrgs/arquivos/plano-institucional.

UFSC. Plano de Internacionalização da Universidade Federal de Santa

Catarina. Florianópolis: Secretaria de Relações Internacionais, Universidade Federal de Santa Catarina, 2018. Disponível em: http://novaprpg.paginas. 
ufsc.br/files/2019/02/PROPOSTA-DE-PLANO-INSTITUCIONAL-DEINTERNACIONALIZAC\%CC\%A7A\%CC\%830-Final-Aprovada.pdf.

UNB. Plano de Internacionalização da Universidade de Brasília. Brasília: UnB, 2018. Disponível em: http://www.int.unb.br/br/institucional/plano-de-internacionalizacao.

UNOESC. Plano de Internacionalização da Universidade do Oeste de Santa Catarina. Joaçaba: Editora Unoesc, [s.d.]. Disponível em: https://www.unoesc.edu.br/images/ uploads/atendimento/Plano_de_Internacionalizac\%cc\%a7a\%cc\%83o_(1).pdf. 